\title{
Complementary feeding hygiene practice and associated factors among mothers with children aged 6-24 months in tegedie district, Northwest Ethiopia: Community-based cross-sectional study
}

Habtam ayenew Teshome ( $\square$ habtam12ayenew@gmail.com )

Primary Children's Medical Center: Primary Children's Hospital

Walelegn Worku Yallew

Addis Ababa University Faculty of Medicine: Addis Ababa University School of Medicine Jember Azanaw

Gondar College of Medical Sciences: University of Gondar

Gardew ayanew Tadege

Gondar College of Medical Sciences: University of Gondar

Agerie Mengistie zeleke

Teda Health Science College

\section{Research}

Keywords: complementary feeding, hygienic practice, children aged 6-24 months, Tegedie district

Posted Date: November 23rd, 2021

DOI: https://doi.org/10.21203/rs.3.rs-1076032/v1

License: (c) (1) This work is licensed under a Creative Commons Attribution 4.0 International License.

Read Full License 


\section{Abstract}

Introduction

The hygienic practices of mothers during complementary feeding are crucial in the protection of vulnerable infants and children aged 6-24 months from childhood communicable diseases like diarrhea and malnutrition. However, sufficient evidence on the hygienic practices of mothers during complementary feeding and their associated factors is limited.

Objective

To determine the levels of complementary feeding hygiene practice and its associated factors among mothers of children aged 6-24 months in the Tegedie district, northwest Ethiopia.

Methods

A community-based cross-sectional study was conducted from March 17 to April 17, 2021, among 576 mothers with children aged 6-24 months in the Tegedie district, northwest Ethiopia. A multistage sampling technique was used to select the study participants. Data were collected using a structured questionnaire administered by an interviewer and entered into Epi-data version 4.6 before being exported to SPSS version 20.0 for data cleaning and further analysis. Bivariate and multivariable binary logistic regression analyses were employed to identify predictors of complementary feeding hygiene practice with $\mathrm{p}$-value $<0.25$ that entered into the multivariable logistic regression model. Then variables with a $p$-value of 0.05 in multivariable logistic regressions were considered statistically significant.

Results

The prevalence of hygienic practice during complementary feeding of their children aged 6-24 months was $33.6 \%$, with $95 \% \mathrm{Cl} 29.7-37.6 \%$ ) of them had good practice. Living in an urban area [AOR=7.02, 95\% $\mathrm{Cl}:(4.14,11.88)]$, the presence of a handwashing facility near the latrine $[\mathrm{AOR}=3.02,95 \% \mathrm{Cl}:(1.18,7.70)]$, the presence of a separate area to store raw and cooked foods [AOR $=5.87,95 \% \mathrm{Cl}:(2.84,12.13)]$, and the presence of a three-compartment dish washing system $[A O R=5.70$,

Conclusion and recommendation

The prevalence of good hygienic practices during complementary feeding among mothers is still low; the district health office and health extension workers should work to improve maternal hygienic practices during complementary feeding.

\section{Introduction}

The World Health Organization (WHO) defines complementary feeding(CF)as the process that starts when breast milk alone is no longer sufficient foods and liquids are needed to meet the nutritional 
requirements, along with breast milk[1, 2]. Guidelines for infant and young child feeding indicators recommend that breastfeeding should begin at 6 months and continue for two years or longer in normal conditions, and complementary foods should be hygienically prepared, stored, and fed with clean hands using clean utensils rather than bottles and teats[1, 3]. It is a transition from exclusive breastfeeding to family foods and a very critical time in which poor hygiene practice of CF in many young children contributes significantly to the high prevalence of gastrointestinal and respiratory illnesses[4]. Gastrointestinal diseases associated with preventable food-borne bacteria for children <2 years of age remain a global health challenge since they have immature immune systems and are vulnerable to infections with enteric pathogens[5].

Hygienic practices during the CF of infants and children play a major role in the occurrence of childhood diarrheal diseases [6]. Studies have shown that diarrheal incidence increases at the age when complementary foods are usually introduced, as unhygienic preparation and handling of foods can be a source of diarrheal pathogens [7-9]. Diarrhea is associated with malabsorption of significant nutrients, fluid losses, and reduced appetite[10], which results in severe childhood nutritional problems such as wasting and stunting [11]. Although hardware components such as improved water supplies and sanitation facilities make it easier to practice, better hygiene can make a huge difference to health, especially in keeping children safe from infection through feeding contaminated foods [12]. Improving hygienic complementary feeding is given special attention in the Sustainable Undernutrition Reduction in Ethiopia (SURE) program. It collaborated with multi-sector intervention to deliver a complex multicomponent intervention to improve child feeding and reduce stunting [13].

Worldwide, the lives of approximately 525,000 children are lost each year from 1.7 billion cases of different infectious diseases like childhood diarrhea, with the highest mortality rates reported among children aged less than 2 years in South Asia and sub-Saharan Africa [14]. Furthermore, 230,000 die every year globally because of diarrheal diseases associated with complementary food contamination [3].The contaminated complementary feeding process is directly related to malnutrition, which is estimated to be the underlying cause of $45 \%$ of all deaths in children under the age of 5 years [15]. About $88 \%$ of child deaths were as a result of a diarrheal diseases that is attributed to poor access to Sanitation, Water, and Hygiene (WASH) services, which may be prevented through improvements in WASH[16].

Epidemiological data indicate that food could be more important than water in transmitting diarrheal diseases, and it is estimated that $40 \%$ of the burden of food-borne disease lies with children aged less than 5 years in African countries[4]. This corresponds with reports that at least $70 \%$ of diarrhea-related pathogens among children could be caused by contaminated complementary foods [15].In Africa, more than $30 \%$ of children aged less than five years of age suffered from different microbial pathogen diseases. Scientific evidence indicates that poor hygienic practices during complementary feeding can have profound consequences for the growth, development, and survival of infants and children[17, 18]. This is explained by a study conducted in Malawi that reported that $27 \%$ of $6-24$ month children were reported to have had diarrhea in the 2 weeks after the initiation of CF that resulted in $80 \%$ suffering from reduced height, growth rate, and $20 \%$ being underweight [19]. Across the three studies in rural India, they 
show that the prevalence of child stunting ranged from 25-50\% [20]. Descriptive study in Malawi showed that the prevalence of diarrhea among the under-fives was $43.4 \%$, and that this diarrhea was among children whose mothers who prepared their children food on the floor was $45.5 \%$ and the table $40.7 \%$, and those who used only water (48.2\%) and 40.3 used soap and water for hand washing[19]. Hand washing and basic hygiene behavior during the preparation of complementary food could minimize the spread of germs and, as such, prevent diarrhea, acute respiratory infections such as influenza, and skin infections [21].

According to the Mini Demographic and Health Survey, 2019 of Ethiopia, the current prevalence of CF was $13 \%$, in addition to breast milk, and infant mortality was $43 \%$ due to preventable bacterial pathogen causing diseases. Inadequate food hygiene is considered to be one of the major contributors to diarrhea [22]. Appropriate CF practice requires good hygienic preparation of complementary preparation, sufficient household-level food availability, and adequate nutritional knowledge application by caregivers [23].Many studies explain that the incidence of diarrheal diseases is especially high after initiation of complementary feeding which is the result of the consumption of contaminated complementary foods that may introduce diarrhea-causing pathogenic microorganisms[24, 25].

Understanding the risk of hygiene practices in complementary feeding is a major concern in Ethiopia for preventing and controlling food-borne diseases in children aged 6-24 months. However, the implementation of these conditions is often limited in Ethiopia. On top of this, there is the problem of real hygiene practices of complementary feeding, resulting in serious consequences of poor health outcomes. Scholars suggested that evidence-based awareness creation on poor practice of complementary feeding, increasing the accessibility of health education for caregiver mothers are recommended to reduce child morbidity and mortality [25]. As far as my knowledge, there is a limited study done on the level and associated factors of complementary feeding hygiene practice among mothers of children aged 6-24 months in Ethiopia. Improving food hygiene practices play a great role in child morbidity and mortality. However, determinant factors of poor complementary feeding hygienic practice is not well addressed which may be important to offer the proper information about those who are vulnerable child age groups. Therefore, the present study aimed to assess the on level and associated factors of complementary feeding hygiene practice among mothers of children aged 6-24 months in Tegedie District Northwest, Ethiopia.

\section{Materials And Methods}

\section{Study area, design and period}

This study was conducted in Tegedie district which is located $115 \mathrm{~km}$ from central Gondar and $748 \mathrm{~km}$ from Addis Ababa (capital city of Ethiopia). The district has one primary hospital, four governmental health centers, 24 health posts, seven private medium clinics. The district is structured into 21 (2 urban and 19 rural) Kebeles. According to Tegedie district health office reports, a total of 96,035 (48,497 male and 47,537 female) population is living in the district. The number of breastfeeding mothers in the district 
was 4026. A community-based cross-sectional study was employed in Tegedie district from March 17 to April 17, 2021.

\section{Study population}

All mothers/caregivers with children aged 6-24 months in the randomly selected kebeles in the district were considered as the study population. Mothers with children aged 6-24 months who were seriously ill and unable to hear and those mothers who lived a minimum of six months and did not start complementary feeding at the time of data collection were also excluded from the study.

\section{Sample size and sampling technique}

The sample size (n) was determined by using the formula for a single population proportion taking an estimate of $\mathrm{P}=38.9 \%$ from previous research conducted in Bahir Dar Zuria district Northwest Ethiopia[26], $Z_{a / 2}=1.96$ is the critical point for the standard normal tabulated value at $95 \%$ confidence interval, and $d=5 \%$ of margin of error. The final sample size, including a $5 \%$ non-response rate and considering 1.5 design effects, was 576 .

The multistage sampling technique was used to get the study participants. Out of 21 kebeles in Tegedie District, 7 (30\%) kebeles were selected using a simple random sampling technique. The sample size was proportionally allocated to each selected kebele based on the size of the population of mothers with 624 month old children in each kebele. The list of mothers with 6-24 month old children in each kebele was used as a sampling frame, which was found in health posts in the respective kebeles. A systematic random sampling technique was used to select the study participants after proportional allocation. The sampling interval $K^{\text {th }}$ value was determined by dividing the total number of mothers with 6-24 children in each by the sample size allocated for each kebele.

\section{Variable}

Dependant variable: Hygiene practices for complementary feeding

\section{Independent variables}

socio-demographic factors (age, marital status, place of residence, and number of children), socioeconomic factors (occupation, level of education, income, residence, and access to media (radio and TV)). Mothers' knowledge and attitudes toward hygienic complementary feeding of children, as well as household and environmental factors such as (the presence and type of latrine, the presence of a hand washing facility near the latrine, the source and quantity of water used per day, the presence of a separate kitchen and a three-compartment dishwashing system).

\section{Operational definition}


Respondents were asked 16 questions ( 6 related to hand washing with water and soap with 3 scales; 1always, 2- sometimes, and 3-wash only with water; and 10 questions related to safety measures during food preparation with a "Yes" or "No" response). The responses forwarded by study participants to the 6 questions related to hand washing with water and soap were dichotomized as 1 "for always" and 0 "for sometimes and washing only with water." The responses forwarded by study participants to 10 questions related to safety measures during food preparation were dichotomized as 1 "for correct" and 0 "for incorrect responses". Those study participants who had the correct response to $75 \%$ of the questions were reported as having good hygienic practice during complementary feeding; otherwise, they were reported as having poor hygienic practice during complementary feeding[27] .

Respondents were asked 20 questions (Cronbach's alpha 0.83) about their knowledge of hygienic complementary feeding, such as; whether they know how to keep their hands safe/clean during food preparation, the critical times for hand washing, the importance of hand washing with soap at critical times, whether respondents know the best way of hand washing during food preparation, the importance of separate storage of raw and cooked foods, whether they know contaminated water can contaminate foods, and whether fruits and vegetables should be washed before eating. The correct answers were coded as 1 and the wrong answers were coded as 0 . The respondent's knowledge questions responses were computed to get the total knowledge score. Those study participants who scored mean (17.04) and above the mean of the sum of the knowledge questions were considered to have good knowledge [25].

\section{Improved water sources}

water sources which include piped water, boreholes or tube wells, protected dug wells, protected springs, and packaged or delivered water. Unimproved water sources include unprotected wells, unprotected springs, and surface water[28].

\section{Data collection and quality control}

Data were collected by interview and observation using a structured questionnaire. The questionnaire was prepared by reviewing previous studies conducted on the hygienic practices of mothers with children aged 6-24 months during complementary feeding of their children [29-31].The questionnaire was comprised of five parts: socio-demographic, household and environmental-related variables, maternal knowledge and attitude about hygienic complementary feeding, and self-reported hygienic practices of mothers during complementary feeding. The questionnaire was developed in English, then translated into Amharic (the local language), and finally back to English to ensure consistency. Five health extension workers as data collectors and one BSC in environmental health as supervisor were recruited for the data collection process.

The pre-test was done on $5 \%$ of the sample size (29 participants) in Kebele, the district where the main study was not undertaken. The training was given for the data collectors and the supervisor on the aim of the study, inclusion and exclusion criteria, data collection technique going through the questionnaires, the art of interviewing, a way of collecting the data, and clarification before the actual data collection. Every 
day after data collection, questionnaires were reviewed by supervisors and principal investigator for ensuring completeness of questions. The completeness of questionnaires was checked before data entry by the principal investigator. Incomplete questionnaires were discarded from the analysis.

\section{Data processing and analysis}

Data were entered into Epi-Data version 4.6 soft ware and exported to SPSS statistical package version 20.0 for further analysis. Descriptive statistics were used to describe the data. Bivariate and multivariable logistic regressions were used to identify predictors of hygienic complementary feeding practice. In Bivariate logistic regression, $p$-value $<0.25$ was considered to retain variables for multivariable logistic regression model. The Hosmer and Lemeshow test were checked to assess the model fitted to conduct logistic regression. A backward stepwise variable selection method was used during multivariable logistic regression to control the confounding effect. Crude and adjusted odds ratios with $95 \%$ confidence intervals were computed to assess the association between independent predictors and outcome variables. A p-value $<0.05$ was considered as level statically of significance.

\section{Results}

\section{Socio-demographic characteristics of participants}

A total of 572 mothers who have children aged 6-24 participated in this study, with a response rate of $99.3 \%$. The mean age of mothers and caregivers was 29.74 years, with an SD of 5.719 . Nearly two-thirds $(374$, or $65.4 \%)$ of the mothers or caregivers who participated in this study lived in urban areas. Nearly two-thirds $(345$, or $60.3 \%$ ) of the mothers or caregivers had no formal education. Similarly, the occupation of more than $329(57.5 \%)$ of the mothers or caregivers was housewife. More than $338(59.1 \%)$ of the households had five or more family sizes. Nearly all 551 (96.3\%) of the mothers/caregivers who participated in this study had one child aged 6-24 months (Table 1). 
Table 1

Socio-demographic characteristics of participants in Tegedie district, northeastern Ethiopia, March 2021

\begin{tabular}{|c|c|c|}
\hline Variable/categories & Frequency (n) & Percent (\%) \\
\hline \multicolumn{3}{|l|}{ Ethnicity } \\
\hline Amhara & 559 & 97.7 \\
\hline Tigray & 8 & 1.4 \\
\hline Others & 5 & 0.9 \\
\hline \multicolumn{3}{|l|}{ Religion } \\
\hline Orthodox & 488 & 85.3 \\
\hline Muslim & 78 & 13.6 \\
\hline Catholic & 2 & 0.3 \\
\hline Others & 4 & 0.7 \\
\hline \multicolumn{3}{|c|}{ Maternal educational status } \\
\hline No formal education & 345 & 60.3 \\
\hline Primary level & 81 & 14.2 \\
\hline Secondary level & 58 & 10.1 \\
\hline Diploma and above & 88 & 15.4 \\
\hline \multicolumn{3}{|l|}{ Maternal occupation } \\
\hline Civil servant & 88 & 15.4 \\
\hline Merchant & 52 & 9.1 \\
\hline Unemployed & 64 & 11.2 \\
\hline Daily laborer & 38 & 6.6 \\
\hline Housewife & 329 & 57.5 \\
\hline Student & 1 & 0.2 \\
\hline \multicolumn{3}{|c|}{ Marital status of mothers } \\
\hline Married & 519 & 90.7 \\
\hline lives separately & 4 & 0.7 \\
\hline Single & 9 & 1.6 \\
\hline Divorced & 31 & 5.4 \\
\hline
\end{tabular}




\begin{tabular}{|c|c|c|}
\hline Variable/categories & Frequency (n) & Percent (\%) \\
\hline Widowed & 9 & 1.6 \\
\hline \multicolumn{3}{|c|}{ Husband educational status ( $\mathrm{N}=523$ ) } \\
\hline Diploma and above & 105 & 20.1 \\
\hline Secondary level & 68 & 13.0 \\
\hline Primary level & 151 & 28.9 \\
\hline No formal education & 199 & 38.0 \\
\hline \multicolumn{3}{|c|}{ Husband occupational status $(\mathrm{N}=523)$} \\
\hline Civil servant & 109 & 20.8 \\
\hline Merchant & 166 & 31.7 \\
\hline Unemployed & 9 & 1.7 \\
\hline Daily laborer & 66 & 12.6 \\
\hline Farmer & 173 & 33.1 \\
\hline \multicolumn{3}{|l|}{ Family size } \\
\hline less than 5 & 338 & 59.1 \\
\hline 5 and above & 234 & 40.9 \\
\hline \multicolumn{3}{|l|}{ No. of under two children } \\
\hline One & 551 & 96.3 \\
\hline More than one & 21 & 3.7 \\
\hline \multicolumn{3}{|l|}{ Household monthly income } \\
\hline Mean and above $(2,756.65)$ & 249 & 43.5 \\
\hline Below mean & 323 & 56.5 \\
\hline \multicolumn{3}{|l|}{ Place of residence } \\
\hline Urban & 374 & 65.4 \\
\hline Rural & 198 & 34.6 \\
\hline \multicolumn{3}{|l|}{ Access to media (TV or radio) } \\
\hline Yes & 288 & 50.3 \\
\hline No & 284 & 49.7 \\
\hline
\end{tabular}




\begin{tabular}{|l|lll|}
\hline Variable/categories & Frequency (n) & Percent (\%) \\
\hline Yes & 85 & 14.9 \\
No & 487 & 85.1 \\
\hline
\end{tabular}

\section{Housing and environmental characteristics}

Of the 572 respondents, the majority of 482 (84.3\%) had latrines of any type for their household members. The most common type of latrine was a pit latrine with slab $239(41.8 \%)$, and almost all 561 $(98.1 \%)$ households obtained drinking water from protected sources. About 510 households had a separate kitchen for food preparation, and nearly 380 households $(66.4 \%)$ used cultural cook stoves for cooking. Other housing and environmental characteristics and the results of the bivariate analysis of their association with complementary feeding hygienic practice among mothers are summarized in (Table 2). 
Table 2

Housing and Environmental of household in Tegedie district, northeastern Ethiopia, March 2021

\begin{tabular}{|c|c|c|}
\hline Variable/categories & Frequency (n) & Percent (\%) \\
\hline \multicolumn{3}{|l|}{ Presence of latrine } \\
\hline Yes & 482 & 84.3 \\
\hline No & 90 & 15.7 \\
\hline \multicolumn{3}{|l|}{ Type of latrine } \\
\hline Pour flush & 21 & 3.7 \\
\hline VIP latrine & 118 & 20.6 \\
\hline Pit latrine with slab & 239 & 41.8 \\
\hline Pit latrine without a slab & 105 & 18.4 \\
\hline No latrine facilities & 89 & 15.6 \\
\hline \multicolumn{3}{|c|}{ Presence of hand washing facility near the latrine } \\
\hline Yes & 29 & 5.1 \\
\hline No & 543 & 94.9 \\
\hline \multicolumn{3}{|c|}{ Handwashing with soap after visiting toilets } \\
\hline Always & 274 & 47.9 \\
\hline Sometimes & 93 & 16.3 \\
\hline Never & 205 & 35.8 \\
\hline \multicolumn{3}{|c|}{ Handwashing with soap after cleaning child's bottom } \\
\hline Always & 276 & 48.3 \\
\hline Sometimes & 91 & 15.9 \\
\hline Wash only with water & 186 & 32.5 \\
\hline Never & 19 & 3.3 \\
\hline \multicolumn{3}{|c|}{ Wash child's hands with soap after he/she defecate } \\
\hline Always & 308 & 53.8 \\
\hline Sometimes & 158 & 27.6 \\
\hline Wash only with water & 106 & 18.5 \\
\hline
\end{tabular}




\begin{tabular}{|c|c|c|}
\hline Variable/categories & Frequency (n) & Percent (\%) \\
\hline Protected water & 561 & 98.1 \\
\hline Unprotected water & 11 & 1.9 \\
\hline \multicolumn{3}{|c|}{ Distance to the water source } \\
\hline In the yard & 185 & 32.3 \\
\hline$\leq 30$ minutes & 196 & 34.3 \\
\hline$>30$ minutes & 191 & 33.4 \\
\hline \multicolumn{3}{|l|}{$\mathrm{HH}$ water treatment } \\
\hline Yes & 62 & 10.8 \\
\hline No & 510 & 89.2 \\
\hline \multicolumn{3}{|c|}{ Presence of separate kitchen for food preparation } \\
\hline Yes & 510 & 89.2 \\
\hline No & 62 & 10.8 \\
\hline \multicolumn{3}{|l|}{ Type of cook stove } \\
\hline Modern stove & 192 & 33.6 \\
\hline Cultural stove & 380 & 66.4 \\
\hline \multicolumn{3}{|c|}{ Presence of separate area to store raw \&cooked foods } \\
\hline Yes & 375 & 65.6 \\
\hline No & 197 & 34.4 \\
\hline \multicolumn{3}{|c|}{ Presence of a three-compartment dishwashing facility } \\
\hline Yes & 266 & 46.5 \\
\hline No & 306 & 53.5 \\
\hline \multicolumn{3}{|l|}{ Knowledge } \\
\hline Good (Mean and above) & 365 & 63.8 \\
\hline Poor (Below mean) & 207 & 36.2 \\
\hline \multicolumn{3}{|l|}{ Attitude } \\
\hline Good attitude & 400 & 69.9 \\
\hline Poor attitude & 172 & 30.1 \\
\hline
\end{tabular}




\section{Knowledge, attitude, and practice of hygienic complementary feeding}

Among 572 mothers/caregivers, 33.6\% (95\% Cl) $(29.7 \%$, 37.6\%) had good hygienic practice during complementary feeding of their children aged 6-24 months. However, $365(63.8 \%)$ and $400(69.9 \%)$ of mothers/caregivers had desirable knowledge and attitude for hygienic complementary feeding (Figure2).

\section{Factors associated with hygienic practices of complementary feeding}

In bivariate logistic regression analysis, urban residence, access to media, maternal educational status, having good knowledge about the hygienic practice of complementary feeding, presence of latrine, having improved latrine, presence of hand washing facilities near the latrine, accessible water source (time taken to reach the source), the habit of treating water in the household, having a separate kitchen from the main house, the presence of a separate storage area for cooked and raw food, and the presence of a three-compartment dishwashing system were candidate variables for the multivariable logistic regression analysis.

A multivariable logistic regression analysis was carried out to evaluate the combined effect of multiple associated factors, adjusting for confounding variables. The results showed that among mothers with children aged 6-24 months, urban residence, the presence of a hand washing facility near the latrine, the presence of a separate area to store raw and cooked foods, and the presence of three-compartment dishwashing facilities had a statistically significant association with hygienic complementary feeding practice.

Accordingly, those mothers/caregivers who lived in urban areas had 7 times [AOR $=7.02,95 \% \mathrm{Cl}$ : (4.14, $11.88)]$ higher odds of practicing good hygienic complementary feeding than those who lived in rural areas.

The odds of good hygienic complementary feeding practice among mothers/caregivers who had a hand washing facility near the latrine were 3 times $[\mathrm{AOR}=3.02,95 \% \mathrm{Cl}:(1.18,7.70)]$ higher compared to mothers/caregivers who had no hand washing facility near the latrine.

Those mothers/caregivers who had a separate area to store raw and cooked foods had almost 6 times higher odds of good hygienic complementary feeding practice than their counterparts $[A O R=5.87,95 \%$ $\mathrm{Cl}:(2.84,12.13)]$. The odds of practicing good hygienic complementary feeding among mothers/caregivers who had a three-compartment dishwashing facility were 5.7 times [AOR $=5.70,95 \%$ Cl: $(3.41,9.54)]$ higher compared to those mothers who did not have (Table 3$)$. 
Table 3

Bivariate and multivariable logistic regression analysis of complementary feeding hygienic practice among mothers who had 6 to 24 months children in Tegedie district, northeastern Ethiopia, March

2021 $(\mathrm{N}=572)$

\begin{tabular}{|c|c|c|c|c|}
\hline \multirow[t]{2}{*}{ Variable/categories } & \multicolumn{2}{|c|}{$\begin{array}{l}\text { Complementary feeding hygienic } \\
\text { practices }\end{array}$} & \multirow[t]{2}{*}{$\operatorname{COR}(95 \% \mathrm{Cl})$} & \multirow[t]{2}{*}{ AOR $(95 \% \mathrm{Cl})$} \\
\hline & Good & Poor & & \\
\hline \multicolumn{5}{|l|}{ Maternal education } \\
\hline Diploma and above & 53 & 35 & 1 & \\
\hline Secondary level & 20 & 38 & $\begin{array}{l}2.88(1.44 \\
5.73)^{\star \star}\end{array}$ & \\
\hline Primary level & 24 & 57 & $\begin{array}{l}3.60(1.90 \\
6.82)^{\star \star \star}\end{array}$ & \\
\hline $\begin{array}{l}\text { No formal } \\
\text { education }\end{array}$ & 95 & 250 & $\begin{array}{l}4.00(2.45 \\
6.49) \star \star \star\end{array}$ & \\
\hline \multicolumn{5}{|l|}{ Place of residence } \\
\hline Urban & 165 & 209 & $\begin{array}{l}5.00(3.17 \\
7.88)^{\star \star \star}\end{array}$ & $\begin{array}{l}7.02(4.14 \\
11.88)^{\star \star \star}\end{array}$ \\
\hline Rural & 27 & 171 & 1 & 1 \\
\hline \multicolumn{5}{|c|}{ Access to media (TV or radio) } \\
\hline Yes & 132 & 156 & $\begin{array}{l}3.16(2.19 \\
4.56)^{\star \star \star}\end{array}$ & \\
\hline No & 60 & 224 & 1 & \\
\hline \multicolumn{5}{|l|}{ Presence of latrine } \\
\hline Yes & 175 & 307 & $\begin{array}{l}2.45(1.40 \\
4.28)^{\star \star \star}\end{array}$ & \\
\hline No & 17 & 73 & 1 & \\
\hline \multicolumn{5}{|l|}{ Type of latrine } \\
\hline Improved & 151 & 227 & $\begin{array}{l}2.48(1.66 \\
3.71)^{\star \star \star}\end{array}$ & \\
\hline Unimproved & 41 & 153 & 1 & \\
\hline \multicolumn{5}{|c|}{ Time is taken to the water source } \\
\hline$\leq 30$ minutes & 147 & 234 & $\begin{array}{l}2.04(1.38 \\
3.02) \star * \star\end{array}$ & \\
\hline
\end{tabular}

Note: The Hosmer and Lemeshow model fitness test p-value was 0.96 . 


\begin{tabular}{|c|c|c|c|c|}
\hline \multirow[t]{2}{*}{ Variable/categories } & \multicolumn{2}{|c|}{$\begin{array}{l}\text { Complementary feeding hygienic } \\
\text { practices }\end{array}$} & \multirow[t]{2}{*}{$\operatorname{COR}(95 \% \mathrm{Cl})$} & \multirow[t]{2}{*}{ AOR (95\% Cl) } \\
\hline & Good & Poor & & \\
\hline$>30$ minutes & 45 & 146 & 1 & \\
\hline \multicolumn{5}{|l|}{$\mathrm{HH}$ water treatment } \\
\hline Yes & 27 & 35 & $1.61(0.94,2.76)$ & \\
\hline No & 165 & 345 & 1 & \\
\hline \multicolumn{5}{|c|}{ Presence of hand washing facility near the latrine } \\
\hline Yes & 20 & 9 & $\begin{array}{l}4.79(2.14 \\
10.75) \star \star \star\end{array}$ & $3.02(1.18,7.70)^{\star}$ \\
\hline No & 172 & 371 & 1 & 1 \\
\hline \multicolumn{5}{|c|}{ Separated kitchen for food preparation } \\
\hline Yes & 187 & 323 & $\begin{array}{l}6.60(2.60 \\
16.76) \star \star \star\end{array}$ & \\
\hline No & 5 & 57 & 1 & \\
\hline \multicolumn{5}{|c|}{ Presence of separate area to store raw and cooked foods } \\
\hline Yes & 181 & 194 & $\begin{array}{l}\text { 15.78(8.31 } \\
29.95)^{\star \star \star}\end{array}$ & $\begin{array}{l}5.87(2.84 \\
12.13)^{\star \star \star}\end{array}$ \\
\hline No & 11 & 186 & 1 & 1 \\
\hline \multicolumn{5}{|c|}{ Presence of three compartments dishwashing facility } \\
\hline Yes & 149 & 117 & $\begin{array}{l}7.79(5.21 \\
11.66)^{\star \star \star}\end{array}$ & $\begin{array}{l}5.70(3.41 \\
9.54)^{\star \star \star}\end{array}$ \\
\hline No & 43 & 263 & 1 & 1 \\
\hline \multicolumn{5}{|l|}{ Knowledge } \\
\hline Good & 142 & 223 & $\begin{array}{l}2.00(1.37 \\
2.93)^{\star \star \star}\end{array}$ & \\
\hline Poor & 50 & 157 & 1 & \\
\hline
\end{tabular}

1 = Reference category,

* = Statistically significant at $p<0.05$,

$\star \star=$ Statistically significant at $p<0.01$ and 
$\star \star \star=$ Statistically significant at $p<0.001$

\section{Discussion}

In this community-based cross-sectional study, the overall prevalence of hygienic complementary feeding practice among mothers who had children aged 6-24 months was found to be $33.6 \%, 95 \% \mathrm{Cl}$ : (29.7, 37.6), and factors such as living in urban areas, the presence of hand washing facilities near the latrine, the presence of a separate area to store raw and cooked foods, and the presence of a three-compartment dishwashing system were significant predictors of hygienic complementary feeding practice.

The prevalence of hygienic complementary feeding practices in this study was lower than the prevalence (38.9\%) reported by a study conducted in Bahir Dar Zuria District, Northwest Ethiopia[32]. This might be due to the differences in the study setting, as Bahir Dar Zuria district is located near the capital city of Amhara National Regional State, Bahir Dar, and mothers/caregivers might have better information and water and sanitation access compared to the current study area. Access to better information and water and sanitation services helps mothers and caregivers improve the habit of good hygienic complementary practice.

Similarly, this prevalence was lower than the prevalence (39.6\%) reported by a cross-sectional study conducted in rural Kebeles of the Harari Region, Ethiopia[26]. This might be due to differences in the measurement of the outcome variable. In the study conducted in the Harari region, the sum of the threepoint score scale (always, sometimes, and never) was used to measure the status of hygienic complementary feeding practice. However, in this study, this three-point scale was dichotomized into "Yes" or "No" responses, coded as 1 and 0 respectively, and added to measure the outcome variable.

Similarly, the result in this study was much lower than the prevalence (51\%) reported by a study done in Abobo district, Southwestern Ethiopia on model and non-model household mothers [33]. This discrepancy might be due to differences in the measurement of good hygienic practice and the comparative nature of the previous study, which included model households that have a higher tendency to adopt good food hygiene behaviors.

The study also revealed that urban residences, the presence of hand-washing facilities near the latrine, the presence of a separate area to store raw and cooked foods, and the presence of three-compartment dishwashing facilities showed a statistically significant association with hygienic complementary feeding practice among mothers who had children aged 6-24 months.

Living in urban areas was a significant predictor of good hygienic complementary feeding practice among mothers with children aged 6-24 months. The odds of good hygienic complementary feeding practice were higher in mothers/caregivers who lived in urban areas compared to mothers/caregivers living in rural areas. A similar finding was reported by a cross-sectional study conducted in the Bahir Dar Zuria District, Northwest Ethiopia[32]. This might be due to the fact that mothers in urban areas might 
have access to information and an adequate supply of water, which helps them to improve the habit of good hygienic practices.

In this study, the presence of a hand washing facility near the latrine was associated with good hygienic complementary feeding practice. This finding is supported by a study conducted in Bahir Dar Zuria District, Northwest and Abobo District, Southwest Ethiopia[32, 33]. The reason for this association is that the presence of a hand washing facility near the latrine inevitably promotes hand washing after visiting the toilet, which helps to adopt hygienic practices in day-to-day activities, especially during food preparation.

Strength and limitations: The community-based nature of the study could be taken as the strength of this study. However, the possibility of social desirability bias could be taken as the limitation of this study. Moreover, this study shares the drawbacks of the cross-sectional study design, as it can't determine the temporal relationship between the predictor variable and the outcome variable.

\section{Conclusions and recommendations}

The prevalence of good hygienic practice during complementary feeding among mothers who had children aged 6-24 months was still low in the study area. This study also revealed that the observed prevalence of hygienic practice during complementary feeding was very low compared to previous studies in Ethiopia. The study also discovered that among mothers with children aged 6-24 months, urban residence, the presence of a hand washing facility near the latrine, a separate area to store raw and cooked foods, and the presence of three-compartment dishwashing facilities had a statistically significant association with hygienic complementary feeding practice.

The district health office should design a health education program for both urban and rural mothers with children about the importance of hand washing facilities near the latrine, a separate area to store raw and cooked foods, and a three-compartment dishwashing system in developing the habit of safe and hygienic preparation of foods.

The low prevalence of hygienic complementary feeding practices can be improved by providing training for mothers, and the women's health development armies' weekly discussion agendas should include the plan to raise issues related to hygienic complementary feeding to facilitate the sharing of information and increase the awareness of mothers. Therefore, health extension workers should design training programs on hygienic food preparation, especially during complementary feeding.

\section{Abbreviations}

AOR stands for Adjusted Odds Ratio. CF stands for Complementary Feeding, COR stands for Crude Odds Ratio, ETB stands for Ethiopian Birr, HEW stands for Health Extension Worker, and HHs stands for Households. 


\section{Declarations}

\section{Acknowledgments}

We would like to acknowledge the Tegedie district health offices and catchment health centers for giving us relevant information and support letters for data collection for this thesis research and health extension workers for their genuine support in the data collection processes. We sincerely appreciate all the data collectors, supervisors, and study participants for their cooperation during data collection.

Funding: None

\section{Availability of data and materials}

The datasets used and/or analyzed during the current study are available from the corresponding author on reasonable request.

\section{Author Contributions}

HA: Methods include HA, WW, JA, GT, and AM.AS; AS, HA, and WT formal analyses; Report writing: AS, HA, and WT Manuscript preparation: HA. All authors read and approved the final version of the manuscript.

\section{Ethics approval and consent to participate}

Before data collection, ethical approval was obtained with ref No/IPH/1499/2013 on date 16/07/2013 from the institutional review committee institute of public health, College of Medicine and Health Sciences, University of Gondar. A permission letter was also obtained from the Zonal Health Department and District Health Offices. Verbal informed consent was obtained from each study participant. The respondents were also informed that they had the full right to withdraw or refuse at any time from the interview. The confidentiality of information given by each respondent was kept properly.

\section{Consent for publication}

Not applicable.

Competing interests: The authors declare that they don't have any conflict of interest in any aspect of the article.

\section{References}

1. Organization, W.H., Complementary feeding: report of the global consultation, and summary of guiding principles for complementary feeding of the breastfed child. report of the global consultation, 2003. 
2. Gautam, O., Food hygiene intervention to improve food hygiene behaviours, and reduce food contamination in Nepal: an exploratory trial. 2015, London School of Hygiene \& Tropical Medicine.

3. Jones AD, I.S., Smith LE, et al, World Health Organization infant and young child feeding indicators and their associations with child anthropometry: a synthesis of recent findings Matern Child Nutr doi:10.1111/mcn.12070, 2014. 10(1):1-17.

4. Das, S., et al., Not water, sanitation and hygiene practice, but timing of stunting is associated with recovery from stunting at 24 months: results from a multi-country birth cohort study. Public health nutrition, 2020: p. 1-10.

5. Gizaw, Z., W. Woldu, and B.D. Bitew, Child feeding practices and diarrheal disease among children less than two years of age of the nomadic people in Hadaleala District, Afar Region, Northeast Ethiopia. International breastfeeding journal, 2017. 12(1): p. 1-10.

6. Shati, A.A., et al., Occurrence of Diarrhea and Feeding Practices among Children below Two Years of Age in Southwestern Saudi Arabia. International journal of environmental research and public health, 2020. 17(3): p. 722.

7. Ehiri, J.E., et al., Critical control points of complementary food preparation and handling in eastern Nigeria. Bulletin of the World Health Organization, 2001. 79: p. 423-433.

8. Mattioli, M.C., et al., Hands and water as vectors of diarrheal pathogens in Bagamoyo, Tanzania. Environmental science \& technology, 2013. 47(1): p. 355-363.

9. Oluwafemi, F. and I.N. Ibeh, Microbial contamination of seven major weaning foods in Nigeria. Journal of health, population, and nutrition, 2011. 29(4): p. 415.

10. Gorospe, E.C. and A.S. Oxentenko, Nutritional consequences of chronic diarrhoea. Best practice \& research clinical gastroenterology, 2012. 26(5): p. 663-675.

11. Derso, T., et al., Stunting, wasting and associated factors among children aged 6-24 months in Dabat health and demographic surveillance system site: $A$ community based cross-sectional study in Ethiopia. BMC pediatrics, 2017. 17(1): p. 1-9.

12. Curtis, V., et al., Hygiene: new hopes, new horizons. The Lancet infectious diseases, 2011. 11(4): p. 312-321.

13. Cami Moss, T.H.B., Mihretab Melesse Salasibew, Joanna Sturgess,Girmay Ayana, Desalegn Kuche, Sustainable Undernutrition Reduction in Ethiopia (SURE) evaluation study: a protocol to evaluate impact, process and context of a large-scale integrated health and agriculture programme to improvecomplementary feeding in Ethiopia. BMJ Open . doi:10.1136/ bmjopen-2018-022028, 2018. 
14. Arikpo, D., et al., Educational interventions for improving primary caregiver complementary feeding practices for children aged 24 months and under. Cochrane database of systematic reviews, 2018(5).

15. R. Agustina, T.P.S., S. Satroamidjojo, I. M. J. Boveeoudenhoven, and a.F.J.K. E. J. M. Feskens, Association of food-hygiene practices and diarrhea prevalence among Indonesian young children from low socioeconomic urban areas. BMC Public Health 2013. vol. 13, no. 1

16. Mshida, H.A., et al., Water, sanitation, and hygiene practices associated with nutritional status of under-five children in semi-pastoral communities Tanzania. The American journal of tropical medicine and hygiene, 2018. 98(5): p. 1242-1249.

17. Byrd, K., et al., Differences in complementary feeding practices within the context of the wash benefits randomized, controlled trial of nutrition, water, sanitation, and hygiene interventions in rural Kenya. The FASEB Journal, 2017. 31: p. 165.1-165.1.

18. Abdurahman, A.A., et al., Magnitude and determinants of complementary feeding practices in Ethiopia: A systematic review and meta-analysis. Heliyon, 2019. 5(7): p. e01865.

19. Ntaji, M., P. Oyibo, and J. Bamidele, Food hygiene practices of mothers of under-fives and prevalence of diarrhoea in their children in Malawi. Journal of Medicine and Biomedical Research, 2014. 13(2): p. 134-145.

20. Jee Hyun Rah, A.A.C., Bhupendra Badgaiyan, Victor M Aguayo, and S.A. Suzanne Coates, Household sanitation and personal hygiene practices are associated with child stunting in rural India: a cross-sectional analysis of surveys. BMJ Open :e005180. doi:10.1136/ bmjopen-2014-005180, 2015. 5.

21. Barker J, S.D., Bloomfield SF, Spread and prevention of some common viral infections in community facilities and domestic homes J Appl Microbiol. PMID https://doi.org/10.1046/j.13652672.2001.01364.x 2001. 91(1)(11442709): p. 7-21.

22. Rockville, M., USA: EPHI Ethiopia Mini Demographic and Health Survey Ethiopian Public Health Institute (EPHI) [Ethiopia] 2019.

23. Zongrone A, W.K., Menon P., Infant and young child feeding practices and child undernutrition in Bangladesh: insights from nationally representative data Public Health Nutr [Internet]. Available from: http://www.ncbi.nlm.nih.gov/pubmed/22564370, 2012. 15:4: p. 1697-70.

24. Mitchodigni, I.M., et al., Complementary feeding practices: determinants of dietary diversity and meal frequency among children aged 6-23 months in Southern Benin. Food Security, 2017. 9(5): p. 11171130.

25. Mohammed, S. and D. Tamiru, The burden of diarrheal diseases among children under five years of age in Arba Minch District, southern Ethiopia, and associated risk factors: a cross-sectional study. 
International scholarly research notices, 2014. 2014.

26. Desta Dugassa Fufa, A.A., Awgichew Teshome, Kedir Teji, Fistum Abera, MaledaTefera,etail, Hygienic Practice of Complementary Food Preparation and Associated Factors among Mothers with Children Aged from 6 to 24 Months in Rural Kebeles of Harari Region, Ethiopia. Food Science and Technology 2020. 8(2) p. 34-42.

27. Agustina R, S.T., Satroamidjojo S, Ingeborg MJ, et al, Association of food-hygiene practices and diarrhea prevalence among Indonesian young children from low socioeconomic urban areas BMC Public Health, vol. , 2012. 13, 977.

28. Demmelash, A.A.M., Biruk Demissie, Admasu, Fitalew Tadele, Bayih Eniyew, Tegegne Yitbarek, Getachew Yideg, Hygienic Practice during Complementary Feeding and Associated Factors among Mothers of Children Aged 6-24 Months in Bahir Dar Zuria District, Northwest Ethiopia, 2019.

Environmental and Public Health, 2020. 2020.

29. Gebre Yitayih, K.B., Mahlet Tsegaye, Assessment of Hygienic Practice on Complementary Food among Mothers with 6-24 Months Age Living Young Children in Mohoni Town, North Eastern Ethiopia, 2015. Journal of Immunology, 2015.

30. Henok Dagne, L.B., Muluneh Borcha, Anley Tesfayeand Baye Dagnew, Hand washing practice at critical times and its associated factors among mothers of under five children in Debark town, northwest Ethiopia, 2018. Italian Journal of Pediatrics 2019. 45:120.

31. Alelign Alemu Demmelash, B.D.M., Fitalew Tadele Admasu, Eniyew Tegegne Bayih, Getachew Yideg Yitbarek, Hygienic Practice during Complementary Feeding and Associated Factors among Mothers of Children Aged 6-24 Months in Bahir Dar Zuria District, Northwest Ethiopia Journal of Environmental and Public Health, 2019. 2020: p. 7.

32. Demmelash, A.A., et al., Hygienic Practice during Complementary Feeding and Associated Factors among Mothers of Children Aged 6-24 Months in Bahir Dar Zuria District, Northwest Ethiopia, 2019. Journal of Environmental and Public Health, 2020. 2020.

33. Akoma Okugn, D.W., Food hygiene practices and its associated factors among model and non model households in Abobo district, southwestern Ethiopia: Comparative cross-sectional study. PLOS ONE | https://doi.org/10.1371/journal.pone.0194391, 2018.

\section{Figures}




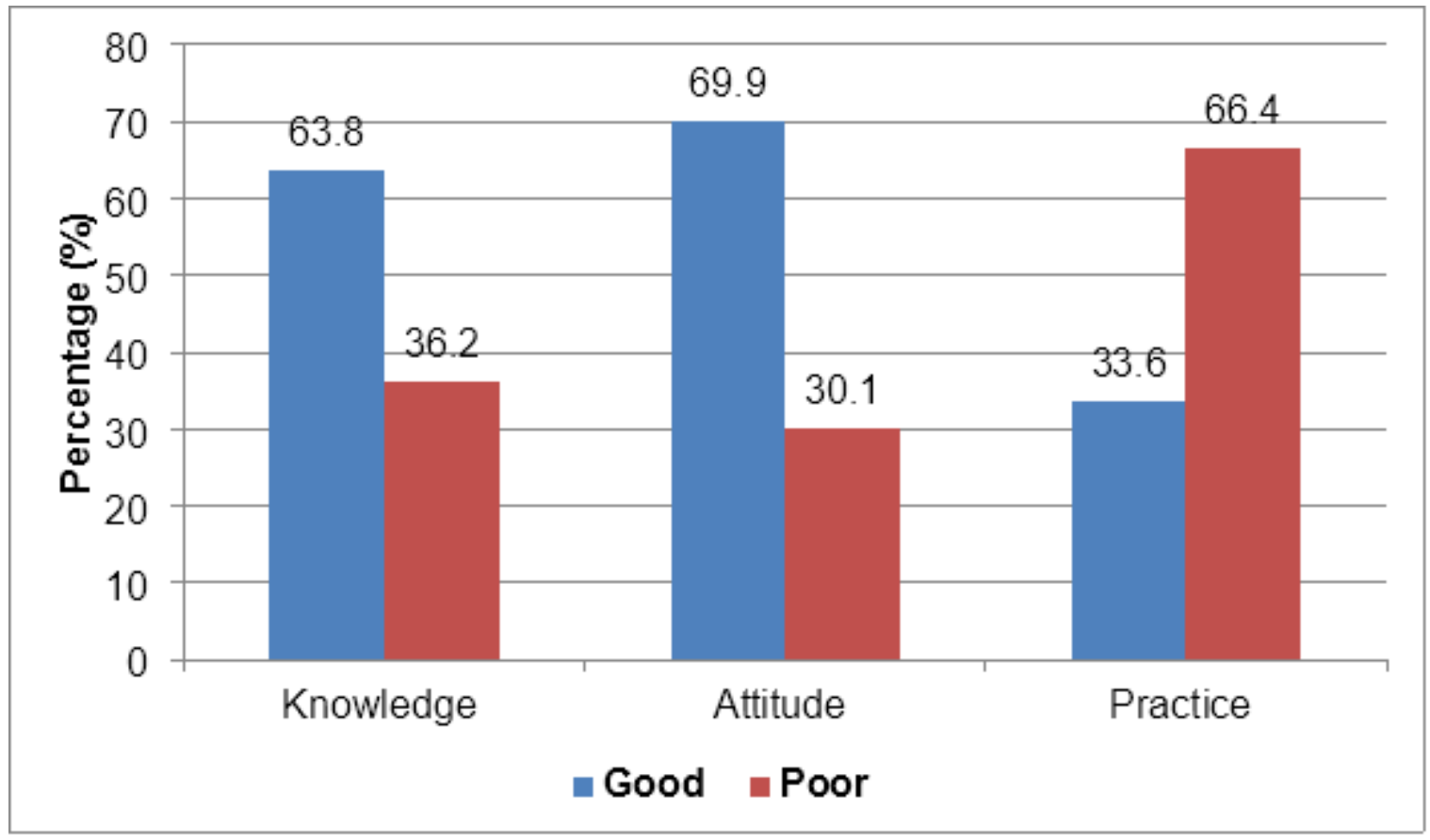

Figure 1

Knowledge, attitude, and practice of mothers/caregivers about complementary feeding their children aged 6-24 months

\section{Supplementary Files}

This is a list of supplementary files associated with this preprint. Click to download.

- Qutiner.docx 